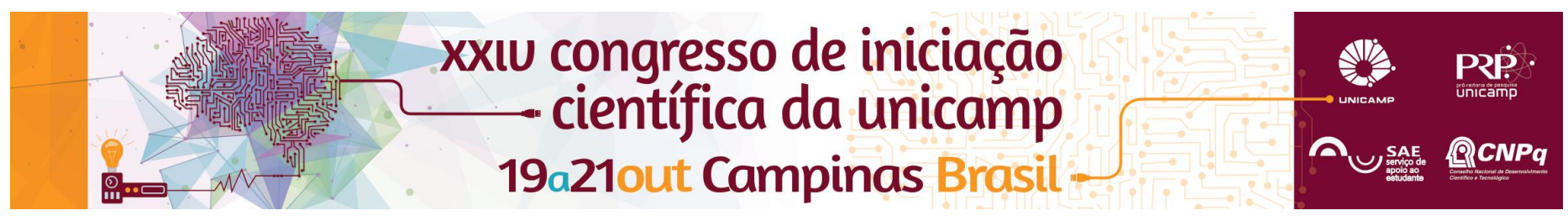

\title{
INDÚSTRIA FARMACÊUTICA E POLÍTICAS GOVERNAMENTAIS NO BRASIL
}

\section{Gabriela Rocha Rodrigues de Oliveira (IC)}

\section{Resumo}

O presente estudo teve como objetivo fazer um mapeamento da indústria farmacêutica brasileira e das políticas industriais governamentais relacionadas ao setor, tanto em uma perspectiva histórica, quanto por meio de uma análise da atualidade, com o enfoque principal em como os resultados apresentados por tal indústria afetam na sustentabilidade e no aprimoramento do Sistema Único de Saúde (SUS) do Brasil.

\section{Palavras-chave:}

Indústria farmacêutica brasileira, Complexo Econômico Industrial de Saúde, Políticas industriais de saúde.

\section{Introdução}

Durante o estudo em questão, buscou-se a compreensão do panorama enfrentado pela indústria farmacêutica brasileira, desde os seus primórdios até o período atual, levando-se sempre em conta a relação que a produção interna de fármacos e medicamentos possui com as políticas públicas industriais e de saúde e com o acesso da população à assistência farmacêutica.

Para tal, foi realizado, a princípio, um levantamento do histórico da indústria farmacêutica no Brasil e das políticas nacionais relacionadas até a década de 1990. Posteriormente, para o estudo do panorama atualizado, procurou-se a compreensão do conceito do Complexo Econômico Industrial de Saúde, das políticas governamentais de incentivo à produção e à inovação na indústria farmacêutica nacional, do panorama industrial enfrentado pelas empresas nacionais nas últimas décadas, além da atuação dos laboratórios públicos e dos gastos em medicamentos realizados no âmbito do SUS.

\section{Resultados e Discussão}

A primeira etapa da pesquisa teve como objetivo realizar um levantamento histórico sobre a constituição e a evolução da indústria farmacêutica no âmbito nacional e na sua inserção internacional em cada período, até a década de 1990. Também se buscou um levantamento das políticas industriais e de saúde realizadas nos diferentes períodos históricos e dos efeitos que estas produziram na estrutura da indústria farmacêutica brasileira. $\mathrm{Na}$ análise da trajetória do setor no Brasil, percebeu-se que, mesmo com diferentes intensidades a cada período, o país sempre foi muito dependente da importação de fármacos e que esse problema nunca foi solucionado e, pelo contrário, agravou-se com as políticas neoliberais que dominaram o país na década de 90, transformando o déficit comercial do setor farmacêutico em um déficit estrutural.

$\mathrm{Na}$ segunda etapa, buscou-se, a princípio, a compreensão do conceito do Complexo Econômico Industrial de Saúde e a sua importância para o sistema de saúde nacional. Também foi feito um levantamento detalhado das políticas industriais relativas ao setor farmacêutico que vêm sendo realizadas no país desde o fim dos anos 90 e como tais ações têm contribuído para o fortalecimento da indústria nacional e do Sistema Único de Saúde (SUS), resultando em um aumento considerável do financiamento público à inovação e das parcerias entre os setores públicos e privados na produção e desenvolvimento de novos medicamentos, considerados estratégicos para o SUS.

Além disso, foram buscados dados relevantes sobre o panorama atual enfrentado pela indústria farmacêutica brasileira, os quais evidenciaram que, apesar de uma relativa melhora em muitos aspectos, principalmente associados ao crescimento da participação de capital nacional no setor e em um grande crescimento de mercado (ambos associados, majoritariamente, ao advento dos medicamentos genéricos no país), há uma fragilidade muito evidente no setor refletida no déficit comercial constante e crescente, associado, em sua maioria, à falta de capacidade produtiva do país no segmento dos fármacos, o que reflete que, por mais que as políticas atuais tenham sido importantes para construir uma maior força da indústria nacional no mercado de medicamentos, muitos esforços ainda serão necessários para que possa existir uma interiorização efetiva da produção de segmentos de maior densidade tecnológica no país, como é o caso dos produtos de base farmoquímica.

\section{Conclusões}

O Brasil, nas últimas décadas, teve grandes avanços relativos tanto à estrutura de sua indústria farmacêutica, quanto à saúde pública de maneira geral. No entanto, muitas lacunas ainda devem ser preenchidas para que se crie um SUS com maior abrangência, qualidade e sustentabilidade e um dos grandes gargalos a serem superados é a promoção de inovação e interiorização tecnológica na indústria de produção de fármacos e medicamentos, o que, no entanto, dificilmente será alcançado se não houver um grande esforço de políticas industriais ativas e precisas que sejam capazes de promover uma maior autonomia e um maior direcionamento da produção farmacêutica brasileira para o atendimento das principais necessidades da população.

\section{Agradecimentos}

Agradeço à minha orientadora, Ana Lucia Gonçalves da Silva, por todo o suporte e ajuda, à minha família, pela eterna inspiração, e ao CNPq, em parceria com a PróReitoria da UNICAMP, pelo apoio financeiro. 